Rev Chil Salud Pública 2012; Vol 16 (3): 288 -298

Traducciones

LUCIANA KIND(1),

CORNELIS JOHANNES

VAN STRALEN ${ }^{(2)} \mathrm{y}$

LETÍCIA GONÇALVES ${ }^{(3)}$

(1)Programa de Postgrado en

Psicología de la Pontificia

Universidad Católica de

Minas Gerais (PUC Minas).

Av. Itaú, $n^{\circ} 525$ - Bairro Dom

Cabral - Belo Horizonte/MG -

CEP: 30535012. Brasil.

lukind@gmail.com

(2) Programa de Postgrado en

Psicología de la Universidad

Federal de Minas Gerais. Brasil.

(3) Estudiante Programa de

Postgrado en Psicología

de la Pontificia Universidad

Católica de Minas Gerais

(PUC Minas). Brasil.

Fuente de apoyo: Fundo de Incentivo à Pesquisa -

Pró-reitoria de Pesquisa

e Pós-graduação da PUC

Minas. / Beca de iniciación científicado CNPq.

\section{La emergencia de concepciones de participación en salud pública*}

\author{
THE EMERGENCE OF THE CONCEPT OF PARTICIPATION IN PUBLIC HEALTH
}

\section{RESUMEN}

El objetivo del trabajo es identificar la emergencia de la noción de participación en salud en las luchas de la salud en Brasil. Con inspiración en la genealogía foucaultiana, más que investigar los orígenes y definiciones consistentes de participación, esperamos identificar ciertas continuidades, encontrar las fuerzas y acontecimientos que revelan los movimientos dispersos, irregulares, montados estratégicamente para tornar la participación palabra de orden y forjar consensos aparentes. Fueron recogidos documentos gubernamentales y académicos, asociados a los términos "participación comunitaria", "participación popular", "participación social" y "participación política. El análisis nos permite asociar la construcción de la linealidad del concepto de participación en tres momentos importantes. El primero respecto al estrechamiento de las relaciones entre OPAS y gobiernos latinoamericanos en los años 1960, difundiéndose la participación comunitaria en las iniciativas de expansión de cobertura. El segundo, envuelve la articulación entre diferentes actores sociales, particularmente entre sanitaristas y técnicos de salud con movimientos populares en los años 1970, rompiendo en el diseño de la participación popular o política. Un tercer momento coincide con la gestación del SUS, que camina para la producción del consenso en torno de la participación social. Esos tres momentos identificados no se caracterizan como rupturas absolutas entre las diferentes denominaciones, ni como una linealidad sin desvíos, pero hacen parte de un proceso de apropiación y reconstrucción del concepto de participación en la salud pública.

Palabras clave: Salud pública, participación comunitaria, sistema único de salud.

\section{THE EMERGENCE OF THE CONCEPT OF PARTICIPATION IN PUBLIC HEALTH}

\section{ABSTRACT}

The objective of this study is to identify the emergence of notions of health participation, in the public health movement in Brazil. Inspired by Foucault's genealogy, this study hopes to identify specific continuities and find strengths and occurrences within the movement, rather than study the origins and definitions of participation. These will reveal disperse, irregular and strategically planned movements which seek to

\footnotetext{
* Kind L, Stralen CJV, Gonçalves L. A emergência de concepções de participação em saúde pública. In: Rasera EF, Castro MM, Stralen CJV. Psicologia Social: ética, participação política e inclusão social. Curitiba: CRV; 2011. p.19-38. Versión actualizada del original.
} 
make participation part of policy and create consensus. A search was carried out to identify government and academic documents with the terms "community participation," "popular participation," "social participation," and "political participation." The analysis allows us to describe the linear development of the concept of participation in three important moments. First, the strengthening of the relationship between PAHO and Latin American governments in the '60s, which expanded community participation along with health care coverage. Second is the articulation between different social actors, particularly between health professionals and technicians, and social movements in the '70s, which influenced the design of social and political participation. The third moment coincides with the creation of the Universal Health System (SUS), which seeks to create consensus in social participation. These are not characterized are three separate moments, nor are they lineal or without diversions, but they form part of the process of appropriation and reconstruction of the concept of participation in public health.

Key words: Public health, community participation, Universal Health System

\section{INTRODUCCIÓN}

Participación es un término adjetivado de variadas maneras en el sector de la salud en Brasil, que comprende conceptos polisémicos desde 1960. Curiosamente, desde la creación del Sistema Único de Salud (SUS) y la institucionalización de la participación en salud en consejos y conferencias, vigora aparente consenso de que en estos espacios es que acontece de modo legítimo. Un significado que acompaña la denominación participación social es tomar parte en procesos decisorios, garantizándose una relación directa entre la población y el Estado. Desde los años 90', participación social se expande en un uso generalizado, ya no son esenciales para discutir los aspectos conceptuales, no sólo las políticas de salud, así como en las prácticas que están destinados a ser "participativas".

Usualmente, hay una narrativa histórica evolutiva y lineal en los límites conceptuales de la participación en salud, en las descripciones que interpretan que hay un camino continuo "de la participación comunitaria a la participación social". A pesar de que estas narrativas guarden margen para cierta variación del adjetivo "social" -política, ciudadana, por ejemplo-, generan un efecto de continuidad que debe ser analizado. Poco se observa de las tensiones y variaciones de los usos e interpretaciones que se presentan en su emergencia en el campo hace varias décadas $^{1-4}$.

En una investigación anterior sobre la práctica de grupo en la atención básica ${ }^{5}$, se observó el uso indiscriminado de la noción de partici- pación. Evidentemente, la participación en las prácticas de grupo no tiene el mismo sentido de participación social según lo establecido en los consejos y conferencias. Sin embargo, la idea de que una práctica es "participativa", se basa en el estatus conquistado por la participación social en el ámbito del SUS. De las inquietudes provocadas por aquella pesquisa desarrolla la cuestión sobre los aspectos históricos del delineamiento de la noción de participación en el campo de la salud.

Por lo tanto, la investigación que aquí se presenta tuvo por objetivo identificar la emergencia de la noción de participación en salud. Con inspiración en la genealogía foucaultiana ${ }^{6-9}$, buscamos desmontar la narrativa de continuidad entre diferentes delineamientos de participación. Más que investigar los orígenes y definiciones consistentes de participación, esperamos identificar ciertas continuidades, encontrar las fuerzas y acontecimientos que revelan los movimientos dispersos, irregulares, montados estratégicamente para tornar la participación palabra de orden y forjar consensos aparentes.

En Nietzsche, la Genealogía y la Historia, Foucault ${ }^{8}$ expone los empleos de la palabra "origen" (Ursprung) en la obra nietzscheana. Entre ellos, se analiza el empleo de "emergencia" (Entstehung) como punto de surgimiento, como la "entrada en escena de las fuerzas; (...) su irrupción, el salto por la cual ellas pasan de los bastidores a la escena, cada una con el vigor y la jovialidad que le es propia" (8, p.269). Considerando esa perspectiva, la genealogía de la noción de participación tiene como objetivo fa- 
vorecer la emergencia de diferentes interpretaciones conceptuales, buscando comprender las fuerzas que están ahí en juego.

\section{Camino metodológico}

Los análisis que serán aquí trabajados se concentraron en la literatura académica y publicaciones de instancias gubernamentales en el área de la salud entre los años 1960 y 1980. Existe un consenso en el uso del término participación social en las publicaciones brasileñas, académicas y gubernamentales tras la sanción de la Ley $8.142 / 90^{10}$. Los demás adjetivos -la participación comunitaria, popular o política- son subsumidos por la definición de participación social. El foco del análisis en las tres décadas que precedieron la Ley 8.142 tiene la intención de encontrar los puntos de confrontación entre las diferentes perspectivas, que culminaron con el formato de cierto consenso sobre la participación social.

Como métodos de recogida de dato se utilizó la pesquisa bibliográfica, entendida como una estrategia metodológica que "implica en un conjunto ordenado de procedimientos de búsqueda por soluciones, atento al objeto de estudio y, por lo tanto, no puede ser aleatorio"11. Se realizaron búsquedas sistemáticas en la Biblioteca Virtual en Salud, utilizando los términos "participación comunitaria", "participación popular", "participación social", "participación política", encontrándose amplia gama de publicaciones, con gran concentración de textos con la primera expresión. Además, se realizaron búsquedas específicas en las colecciones de bibliotecas con interfaz digital (PUC Minas, UFMG y la Biblioteca Digital de la Unicamp). Textos mimeografiados de la colección personal de uno de los autores también compuso el corpus de nuestra investigación $^{12-15}$.

\section{Resultados y propuesta de análisis}

Las lecturas exploratorias nos permitieron componer un foco del material sobre lo cual los análisis se profundizarían, a saber: publicaciones del Boletín de La Oficina Sanitaria Panamericana; Anales de la III SESAC, 1976; legislación brasileña relacionada al tema; y algunos textos específicos $^{3,4}$. Las búsquedas permitieron tam- bién la composición de textos de apoyo, elegidos por su carácter analítico del escenario de salud en importante momento histórico o específicamente sobre el tema de la participación.

La selección del material se concentró en textos gubernamentales y académicos publicados entre las décadas de 1960 e inicio de los años 1990. Esas tres décadas revelan momentos de fuerte discusión polisémica sobre participación, en que emergen diferentes adjetivaciones agregadas al término participación: comunitaria, popular, política, social. El análisis de la emergencia de esas concepciones fue el objetivo de nuestros estudios, en que buscamos identificar las fuerzas en juego, los principales grupos políticos involucrados, los embates, las rupturas y las supuestas evoluciones que se han forjado en torno al concepto.

Una vez identificados los textos iniciales, se procedían las etapas de lectura exploratoria y selectiva, produciendo el conjunto de documentos gubernamentales, artículos, disertaciones y tesis que han sido objeto de lecturas reflexivas y de interpretación. La inspiración en la búsqueda genealógica organizó el abordaje analítico de los textos, en la medida en la que investigamos, como señalan Rabinow y Dreyfuss (1995, p.118), las "discontinuidades allí donde desarrollos continuos han sido encontrados (...) recurrencias y juego allí donde progreso y seriedad forma encuentros".

Una primera observación, particularmente cuando analizamos textos publicados en los años 1960, es que publicaciones gubernamentales y académicas se mezclan. Fueron pocos los textos "puros" analizados. La mayor parte parecía tener circulación de mano dupla. Las mezclas entre recomendaciones internacionales, acciones gubernamentales y el movimiento sanitario brasileño nos ayudan a comprender la interpenetración de los discursos. El análisis de documentos gubernamentales y de textos académicos descortina momentos de diálogo intenso entre universidad y agencias gubernamentales.

El análisis nos permite asociar la construcción de la linealidad del concepto de participación en tres momentos importantes. El primero dice respecto al estrechamiento de las relacio- 
nes entre OPAS y gobiernos latinoamericanos en los años 1960, difundiéndose la participación comunitaria en las iniciativas de expansión de cobertura. El segundo envuelve la articulación entre diferentes actores sociales, particularmente entre sanitaristas y técnicos de salud con movimientos populares en los años 1970, rompiendo en el diseño de la participación popular o política. Un tercer momento coincide con la gestación del SUS, de modo directo, que camina para la producción del consenso en torno de la participación social. Esos tres momentos identificados no se caracterizan como rupturas absolutas entre las diferentes denominaciones, ni como una linealidad sin desvíos, pero hacen parte de un proceso de apropiación y reconstrucción del concepto de participación en la salud pública. Al contrario de producir una nueva linealidad, dividida en tres décadas, intentamos recolocar en movimiento histórico la noción de participación.

En Brasil, durante la década de 1960, el incentivo a la expansión de cobertura de la asistencia a la salud deflagra una amplia discusión sobre participación comunitaria. En la década siguiente, la noción de participación comunitaria sufre críticas contundentes por haberse revelado insuficiente para impactar decisiones que sobrepasaban una dimensión local. Las principales críticas polarizan descripciones distintas de participación o vertientes contrastantes en el análisis de las prácticas participativas ${ }^{1-3,12,17}$. En el escenario internacional, "participación comunitaria" es reforzada en la Declaración de Alma Ata, al final de la década de $1970^{18}$. No obstante, basándose en las experiencias de expansión de cobertura, de las alianzas entre movimientos populares y el movimiento sanitarista, se elige como punto de llegada la concepción de participación social. Las discusiones en la $8^{a}$ Conferencia Nacional de Salud ${ }^{19}$ nos ayudan a identificar la dimensión estratégica de uso de esa noción que pasaría a imponerse como unívoca para comprenderse participación en salud.

La profundización de esas cuestiones es expuesta en tres ejes de discusión en los cuales se destacan, respectivamente, la participación comunitaria, la participación popular y la participación social.

\section{Producción de la participación comunitaria en latinoamérica}

En la década de 1960 las publicaciones de la Organización Panamericana de Salud (OPAS) endosan los acuerdos para el desarrollo de países latinoamericanos presentes en la Carta de Punta Del Este ${ }^{20,21}$. Celebrada como el establecimiento de la Alianza para el Progreso, el documento preconiza la búsqueda de los países signatarios por la aceleración del progreso económico, por "amplia justicia social para sus pueblos, respetando la dignidad del hombre y la libertad política"20. El preámbulo de la Carta de Punta Del Este hace referencia a las luchas por libertad en las naciones latinoamericanas, recomendando la impresión de un "nuevo sentido a esa vocación revolucionaria".

Esas recomendaciones reverberan la influencia estadounidense del gobierno Kennedy, demandando la disminución de las tensiones sociales en esos países de modo así de evitar otras revoluciones -como la cubana- en el continente $e^{22-24}$. Del punto de vista de la salud, las recomendaciones de la Carta de Punta del Este son interpretadas como el perfeccionamiento de la capacidad de la población de mejorar sus condiciones de vida. Entre los criterios para determinar los problemas prioritarios de salud, se lista la demanda de la población. Se creía que la "participación activa e informada de la comunidad" deflagraría actitudes de colaboración e interés para la solución de los problemas de salud ${ }^{21}$.

Guevara y colaboradores ${ }^{23}$ acentúan que la formación de sanitaristas en la posguerra para combate de endemias, se volvía al desarrollo de campañas sanitarias contra enfermedades infecciosas (Américas Latina y Central). Para combatir necesidades sociales, se incentivaba la creación de una "sólida opinión pública, bieninformada, con bases suficientes para opinar y con peso en las decisiones que la afectan" ( $p$. $88)$, es decir, se invertía en una incipiente propuesta de participación de la comunidad en la solución de los propios problemas. Denominada como participación comunitaria, con propuesta de que la propia comunidad se organizara de manera de solucionar sus problemas de salud, esa era la modalidad de envolvimiento que se 
esperaba de la población. Los autores colocan en relieve la paradoja de que, por un lado, se proponía que la comunidad participara directamente en la construcción de la salud local y, por otro lado, el poder de decisión permanecía en el control del Estado. El formato "esfuerzo de grupo" refleja las expectativas de participación de la comunidad, convocada a ofrecer "mano de obra, material y, a veces dinero para la instalación de servicios básicos". Al Estado, cabía la designación de técnicos "ayuda financiera y la definición de lo que se debe hacer." (23, p. 89)

Los autores destacan que desde el año 1950 comienza el incentivo para la participación de la comunidad en la solución de sus problemas. El gatillo del pensamiento del desarrollo es la creación de la Comisión Económica para América Latina (Cepal), órgano de la ONU, vuelto para el desarrollo industrial y la planificación en los países en desarrollo creado en 1948. El impulso del desarrollo relega la participación comunitaria a un segundo plano. Solo en la década de 1970, regresa a la participación comunitaria como la capacidad de integrar a los sectores marginados del proceso de desarrollo. Desde la III Reunión de Ministros de Salud para las Américas, emergió la preocupación con la extensión de cobertura de asistencia a la salud, cuyo elemento decisivo sería la organización de la comunidad.

En la época, se intentó desarrollar una definición de participación comunitaria, al apuntarla como un proceso por el cual la comunidad, a través de sus formas organizativas, altera la distribución del poder vigente en la sociedad (...). El análisis de esa propuesta dio lugar a un enriquecimiento del debate, resaltándose, entre los conceptos más importantes, que, sin intentar una definición, porque es dispensabl la participación comunitaria es un espacio político para la lucha en el campo de la salud; que se debe denunciar la naturaleza meramente racionalizadora (y no transformadora) de las propuestas de participación comunitaria de algunos técnicos. (23, p.98-99, nuestro énfasis).

La "dispensable" distinción entre los diferentes adjetivos presentes cuando la publicación del trabajo no debería impedir el "avance" a una comprensión transformadora de la participación en salud. Sin embargo, los autores presentan el nombre de la participación popular, que se define como el "ejercicio real del poder por parte del pueblo organizado en vez de la cooperación del pueblo en el desarrollo de las actividades decididas por la clase dominante por las estructuras del poder de clase." (23, p. 95-96).

Es de destacar que esta producción proviene de la preparación de un curso para directivos y técnicos en América Latina, un momento de apertura política en Brasil, con los directivos y académicos como autores identificados con el movimiento salud en Brasil. Producido después de la Declaración de Alma-Ata, que legitima internacionalmente las propuestas de participación comunitaria, el texto nos recuerda que este diseño puede tener diferentes significados según el contexto en el que se utiliza. En este punto, los autores exponen una polarización entre propuesta de desarrollo de la comunidad como mantenimiento del statu quo, y en un polo opuesto, hubo "propuestas realizadas por países que han pasado por transformaciones radicales en su estructura político-económica, en que el pueblo organizado tomó el poder". (23, p.98). Entre estos polos, según los autores, habría una serie de ajustes intermedios.

A pesar de los diferentes contornos que la participación comunitaria podría tener durante la interferencia de organismos internacionales, los autores sostienen la necesidad de entenderlo como "el ejercicio del poder político", superando eventuales dilemas en torno a su definición durante las propuestas de desarrollo en América Latina.

Poca publicación académica brasileña sobre la recepción de estas recomendaciones, que data de la década de 1960 fue encontrada. En el régimen militar, con la restricción de las libertades políticas, Brasil estaba viviendo "el vacío político provocado por la represión”, añade Ferreira ${ }^{25}$, destacando lo que el autor describe como "retórica del compromiso técnico" experimentado en el país en la década de 1960.

Mientras tanto, en los intersticios de la represión y la restricción de las libertades políticas elaboran acciones vinculadas a la iglesia de movilización popular ${ }^{26,27}$. Los pensamientos libertarios de Paulo Freire ${ }^{28,29}$ construidos a finales de aquella década, animarían, en gran parte al lado 
de las teorías marxistas, una primera polarización entre participación comunitaria y participación popular.

En la década de 1970, cuando se inicia la apertura democrática en el país, se observa creciente capilaridad de relaciones entre universitarios, técnicos de salud y educadores populares con la población de baja renta, construyendo una ola de discusiones sobre participación popular o política.

\section{¿De la participación comunitaria a la participación popular?}

El fracaso del modelo de desarrollo, junto con la tecnocracia del régimen militar condujo la amplia revisión de procesos organizativos de las poblaciones marginadas. En contrapartida, la creciente movilización popular y las intensas relaciones entre técnicos y académicos y la sociedad civil en proceso de organización tomaba escena de las formulaciones sobre participación en salud.

Los organismos internacionales no eran ajenos a la necesidad de un nuevo discurso sobre la participación. Tema destacado en el Plan Decenal para las Américas, la participación comunitaria se describe como un elemento indispensable para el desarrollo de una conciencia cívica. El proceso de organización comunitaria se considera como una forma de aprovechar el potencial de involucrar a la población para lograr mayores niveles de vida. El documento enfatiza que es esencial escuchar las demandas de la población y su participación en la toma de decisiones $^{30}$. En el informe de reuniones técnicas la OPAS recomienda:

El proceso de participación debe abarcar a toda la población de un país y para que ello se cumpla es necesario que la comunidad se organice. Esta organización implica la necesaria voluntad de intervención activa de toda la población, incluyendo a los organismos gubernamentales o privados que promueven la participación (...). La participación de la comunidad en la toma de decisiones varía según la naturaleza del contenido de la participación y las circunstancias en las cuales se lleva a cabo. Puede ir desde la simple intervención al emitir opiniones y juicios hasta adoptar la decisión propiamente dicha. (31, p.31).
Las ambigüedades generadas por ese continuum desde opiniones hasta la toma de decisiones propiamente dichas justifican las cuestiones abordadas por Stralen ${ }^{1}$ sobre las condiciones políticas para garantizarse la participación. Reflexionando sobre los contornos de una participación "funcional" y otra "concientización", el autor enfatiza esa ambigüedad del discurso gubernamental sobre participación de la comunidad.

El "enfoque funcional" de la participación se refiere al polo de "opiniones", como un medio de obtener apoyo oficial para programas gubernamentales, aprovechándose mejor los recursos de la población. Tendría, por tanto, una finalidad de garantizar la adhesión de la población. La participación se situaría en la ejecución de tareas prescritas por los técnicos y gestores, en un espíritu de colaboración. La participación de la población en procesos decisorios no está prevista aunque se acuñe una justificativa de que la población no esté lista para eso.

El "foco de concienciación" tendría como objetivo "llevar al individuo a descubrir su verdadera situación y organizarse y capacitarse a partir de esto". La población participa del diagnóstico de los problemas que enfrenta de modo a elaborar soluciones. Ese enfoque de participación se pautaría por una comprensión amplia de salud, interdependiente de otros sectores (educación, trabajo, habitación, y así sucesivamente).

Lo que definirían la elección por un enfoque u otra serían factores económicos y políticos y las condiciones políticas. Teniendo eso en cuenta, se apunta las dificultades encontradas por técnicos y planificadores en iniciativas de participación de la población. Una primera dificultad sería la orientación de técnicos y planificadores para modelos teóricos poco relacionados con cambios de comportamiento. Otro punto sería la de elaborar de arriba hacia abajo las acciones de salud, sin mapeo de las necesidades reales y, por consiguiente, no logrando la cooperación de los líderes locales. Por el contrario, los programas de salud que se basan en la demanda local correría el riesgo de no garantizar la viabilidad política para tratar las cuestiones, intensificándose tensiones sociales.

Para llegar a posibles soluciones, Stralen ${ }^{1}$ argumenta que la "real participación de la po- 
blación" parte de un conocimiento crítico de la realidad. Para ello, la gente debe tener canales de representación capaces de "influir en las decisiones regionales y nacionales." En una nota breve, el autor reflexiona: "El enfoque de concienciación es un abordaje educativo, en la medida en la que parte del conocimiento crítico de la realidad y busca capacitar y organizar los hombres para incidir sobre esta realidad. Sin embargo, nos debemos preguntar si el sistema político permite que un proceso educador lleve la población a organizarse de tal manera que pueda expresar sus intereses y obtener medios para influenciar decisiones. Esto plantea la cuestión de los límites que la situación política y económica actual establece para programas con participación de la población."1

En sus conjeturas acerca de la participación en la salud, el autor utiliza principalmente el término "participación pública". Diferentes adjetivos se unen a ella, haciendo combinaciones como "participación activa / real / efectiva de la población." En otro momento, Stralen ${ }^{14}$ señala la contradicción de la participación comunitaria en los programas de gobierno. Los agentes de salud, percibieron eso gradualmente: "En momentos en que su trabajo significaba alguna amenaza al status quo, o canalizaba reivindicaciones populares para instituciones gubernamentales, las experiencias fueron interrumpidas y los técnicos institucionalmente marginados. Así, fueron descubriendo, a duras penas, que su espacio institucional de trabajo nada valía sin un apoyo popular organizado para defender ese espacio." (14, p.39).

Los movimientos sociales urbanos "crearon un nuevo lugar de participación social y política para las clases populares", generando una democracia "de abajo para arriba". La obstrucción de canales de participación directa para la población había "estimulado el uso de los lazos primarios de solidaridad en la lucha por la supervivencia cotidiana" (14, p.44). Mientras, el autor resalta la timidez de esos movimientos y su frágil visibilidad. La captura de los movimientos populares por luchas más amplias -libertad democrática, por ejemplo- pluralizaba las banderas y la diversidad de intereses se superponen al carácter local de las luchas. Nos inspira a pensar en una identificación mayor del Estado y organismos internacionales con la delimitación de participación comunitaria. Movimientos populares y técnicos de salud adjetivan la participación como social o política, buscando valorar procesos organizativos que reivindican la democratización de las políticas de salud.

En dirección semejante, Herrera ${ }^{32}$ recomienda cautela para la planificación de técnicos de todos los aspectos, ordenando la población. El papel del técnico sería contribuir para la "democratización del conocimiento científico y tecnológico y ponerlo a disposición de la gente para conseguir su superación y participación -consciente y activa- en las acciones; la gente, por su parte, debe también contribuir con sus conocimientos empíricos para la formación social y política de los técnicos." La finalidad de esa relación entre técnicos y población sería la producción de una "nueva conciencia crítica y transformadora". Supone un diálogo racional entre comunidad y Estado.

En la polarización entre la participación de la comunidad -o de la comunidad como una figura en los documentos internacionales, así como en la Ley Orgánica de Salud ${ }^{33}$ - y la participación popular, la última va siendo configurada, especialmente en el ámbito académico y en ciertos espacios de interlocución entre estos y gestores progresistas, como la "participación como debía ser": estructural, activa, consciente y organizada. Por otro lado, la participación comunitaria es narrada como funcional, como mecanismo para facilitar la mano de obra, foco de obediencia a la expectativa estatal, como limitada.

Esa polarización es también expuesta por Stralen, Souza y Vieira ${ }^{13}$. Los autores alertan para el hecho de que la población, en varias oportunidades, asume un carácter particular de participación, reducida a rituales de participación en reuniones, garantía de beneficios personales, en una relación utilitarista con agentes de salud. Mientras, reflejan que la participación comunitaria puede ser, en algunos casos, "un camino para las clases populares sin canales de expresión política que expresen algunos de sus intereses y obtener un control, aunque sea mínimamente, sobre la acción del estado." (13, p.7). Los autores explicitan su sospecha de que 
la participación comunitaria es un recurso ideológico de los responsables por la implantación de programas de salud, siendo difícil localizar en la población la posibilidad de pasarse "de un estado de marginalidad a otro de participación, como dos polos de un continuo no contradictorio." (13, p.10).

\section{La gestación del SUS y la participación social}

Debido a la creciente movilización popular que marcó la apertura democrática en Brasil, la contraposición entre participación comunitaria y participación social o política se hace más evidente al final de los años 1970, cuando se clamaba por nuevas concepciones o modelos de participación capaces de sustentar proposiciones que modificarían el sistema nacional de salud. Revelador del clima político del final de los años 1970, el artículo de Lenita Nicoletti ${ }^{3}$ lleva a los lectores a pensar en la viabilidad de las discusiones sobre participación comunitaria a una efectiva participación política.

Somarriba y Afonso ${ }^{34}$ trazan un recorrido histórico de participación, llamada por ellas como siendo popular, a través de los movimientos sociales. Las autoras discuten la manera como se configura el período autoritario que se inicia en 1964, caracterizado por el "desmantelamiento de los mecanismos de representación y el cierre casi total de los canales de participación popular hasta entonces existente." (p.2). De esta forma, ellas localizan la década de 70 como la época en que las propuestas de participación popular empiezan a ocurrir, fuertemente preparadas por los crecientes programas de salud.

En este contexto, la inserción de los trabajadores de la salud en las disputas electorales garantizó la generalización de ciertos programas como el Proyecto Montes Claros para el contexto nacional ${ }^{34-36}$. El Programa de Interiorización de las Acciones de Salud y Saneamiento (PIASS), cargado de los propósitos políticoideológicos de la experiencia del norte de Minas Gerais, expande sobremanera las discusiones sobre participación popular, alzada a la condición de participación política.

En estudio profundizado sobre la participación popular en salud, Ferreira ${ }^{25}$ apunta que el tema de la participación, desde la redacción del
PIASS fue sistemáticamente incluido en los documentos gubernamentales brasileños, en las palabras de las autoridades públicas, de movimientos sociales y de segmentos académicos. El autor, proponiendo un análisis arqueológico de los discursos sobre participación, caracteriza participación como un conjunto de enunciados que constituyen una "tensa pieza enunciativa".

Para ese autor, los términos que siguen a la participación de la comunidad -la participación popular, participación social, control social y así sucesivamente- están relacionados, en principio, las prácticas participativas. El autor sostiene que "la continuidad del discurso oficial participativo sedimenta la idea de la reforma, de cambios en los patrones de organización y orientación del sistema de salud" (25, p.102).

En un extenso análisis sobre la $7^{a}$ Conferencia Nacional de Salud, Ferreira ${ }^{25}$ revela el poder unificador de la polarización entre participación comunitaria y participación social. El autor trabaja con documentos de discusión del grupo de trabajo de la $7^{\mathrm{a}} \mathrm{CNS}$, donde se lee distinciones entre ambas las nociones, llevando a una delimitación conceptual que valora la segunda (social) en detrimento de la primera (comunitaria). Posterior a la Declaración de Alma Ata y en ella inspirada, la discusión en aquella conferencia acentúa la obsolescencia del término "comunitaria" y la necesidad de construir modalidades de participación que generan cambios sociales profundos, apoyada en pensamiento progresista y libertador.

El informe final de la $7^{\mathrm{a}} \mathrm{CNS}$ testifica que la liberación, resultado del proceso participativo, sólo ocurriría "como objetivo consciente y voluntario". Admite participación -sin adjetivos- como "un lento y trabajoso proceso de interacción, parte y consecuencia de maduración política y desarrollo democrático" (17, p.25).

Establecidas las bases para pensar en la salud como derecho, esa fue la bandera defendida en la $8^{\text {a }}$ Conferencia Nacional de Salud, ocurrida en 1986. Los Anales de la $8^{a}$ Conferencia presentan discusiones proficuas sobre participación social, delimitándola como movilización popular al proponer el establecimiento de una nueva relación entre sociedad civil y Estado ${ }^{19}$. Es defendida la necesidad de control y de poder decisorio de la población sobre las políticas 
de salud. Las conquistas subsiguientes a la $8^{a}$ Conferencia, entre ellas, la garantía de la salud como derecho de los ciudadanos y deber del Estado en el texto constitucional y las Leyes 8.080 y 8.142 que instituyen el Sistema Único de Salud, dirigidos a la configuración de la participación social como la garantía de participación de la población en los Consejos y Conferencias de salud en todas las esferas del gobierno. En habla en la $8^{\mathrm{a}} \mathrm{CNS}$, Machado revela:

Cualquiera sean los propósitos y objetivos del Estado, con la implementación de programas de extensión de cobertura de atención médica, lo cierto es que son disfrutados por los sectores más progresistas de los servicios sanitarios brasileño para llevar adelante prácticas participativas que, si no tienen gran impacto en el sentido de hacer avanzar la democracia, inician un largo y rico proceso de resistencia al autoritarismo del sector. (19, p.301).

El pronunciamiento de Machado refuerza nuestra hipótesis de que más de nuevos conceptos, las diferentes adjetivaciones de participación se producen como estrategias de circulación de las fuerzas en juego expresas por diferentes actores institucionales: agencias internacionales, instancias de gestión estatal, movimientos populares, técnicos e higienistas.

En trabajo más reciente, Escorel y Moreira ${ }^{37}$ alegan que "(...) la participación no puede ser naturalizada como algo positivo en sí mismo ni desvinculada de las relaciones sociales, económicas y políticas" (p.980). Los autores advierten que la participación y democracia son categorías paraguas, que comprende múltiples definiciones. Sin embargo, la opción que hacen es de reproducción del esquema lineal "de la participación comunitaria a la participación social”. La finalidad del capítulo de libro-texto sobre el sistema y las políticas de salud en Brasil es de presentar la participación social como expresión máxima de la relación entre población y Estado, viabilizada como conquista en los consejos y conferencias. Esa opción narrativa, como hemos señalado, transcurre la literatura académica y gubernamental pos- $8^{a}$ CNS.

De modo de comprender esa utilización de la participación social, el texto de Guizardi y Pinheiro ${ }^{38}$ es revelador. Los autores vinculan el surgimiento del SUS y la concepción de partici- pación política, visto que su creación visaba la construcción de la salud como una cuestión de ciudadanía y la participación como condición de su ejercicio. Con base en la Ley 8.142, abordan la propuesta de los Consejos y Conferencias de Salud como espacios de representación institucional, que pretendía garantizar que el control social asumiese lugar estratégico en la definición y ejecución de las políticas de salud.

Como proyecto político, la participación social no pudo renunciar de la denominación "participación comunitaria"10,33. A pesar de los supuestos avances conceptuales operados en las polarizaciones entre participación comunitaria y participación popular o participación social, la expresión participación comunitaria adentra los documentos más decisivos, entre ellos las Leyes 8.080 y 8.142 . La tesis de Ferreira ${ }^{25}$ es de que el enunciado participación comunitaria "testifica su filiación a las propuestas internacionales", no si resolviendo, por tanto, en el campo semántico, "pudiendo ser mejor entendida por el cruce de los compromisos asumidos por sectores de la burocracia de Estado en un momento de transición política (...) con la incorporación de las tesis de los organismos internacionales, donde se encontraba un fundamento ético para la atención prioritaria a las comunidades en desventaja" $(25$, p.137).

\section{Consideraciones finales}

Las ideas presentadas aquí no se interesan en descalificar las inequívocas conquistas en la arena de las prácticas y construcciones político-institucionales de la participación en salud. Se cuestiona la construcción de la trayectoria conceptual como narrativa lineal y evolutiva. Le inscribe en una configuración genealógica, pautando fisuras donde se encuentran definiciones monolíticas y acabadas.

La viabilidad institucional para "pensarse diferente", se entregó, en un determinado momento histórico al uso de una expresión más conciliatoria: participación de la comunidad. En los textos analizados, las descripciones de las diferentes "formas" de participación no siempre son mutuamente excluyentes. En algunos textos en que se llama "participación popular", por ejemplo, puede figurar en otro como "participación política". Ese elemento refuerza nuestra 
búsqueda no por las esencias de las definiciones y el uso más estratégico que los acompañan. La expresión "participación de la comunidad" garantiza la inclusión de la participación en los textos de la Constitución y de las Leyes 8.080 y 8.142 .

Entre los principales textos analizados, cuanto más comprometido en establecerse un diálogo entre académicos y policy makers, más frecuente es el uso de la expresión "participación de la comunidad". Esa noción permanece en las discusiones internacionales.

Los tres momentos identificados no se caracterizan como rupturas absolutas entre las diferentes denominaciones, ni como una linealidad sin desvíos, pero hacen parte de un proceso de apropiación y reconstrucción del concepto de participación en el campo de la salud pública.

\section{Agradecimientos}

A la Pro-Rectoría de Investigación y Postgrado de la Pontificia Universidad Católica de Minas Gerais y al CNPq para la ayuda financiera y concesión de beca de iniciación científica que permitieron el desarrollo de la pesquisa.

\section{Referencias}

1. Stralen CJV. Notas a respeito de participação comunitária em programa de saúde. In: Anais da III semana de estudos sobre saúde comunitária. Curitiba, 13 a 17 de abril; 1976.

2. Stralen CJV. Gestão participativa de políticas públicas: 0 caso dos Conselhos de Saúde. Rev Psicol Polít. 2005;5(10):313-344.

3. Nicoletti L. Planificação em saúde e participação comunitária. Serv Social Soc. 1979;1:92-101.

4. Stralen CJV. Limites e potencialidade da participação da população em programas de saúde [manuscrito]; 1977.

5. Ferreira Neto JL, Kind L. Promoção da Saúde: práticas grupais na Saúde da Família. São Paulo: Hucitec; 2011.

6. Foucault M. Microfísica do poder. $17^{\mathrm{a}}$ ed. Rio de Janeiro: Graal; 2002.

7. Foucault M. Michel Foucault entrevistado por Hubert Dreyfus e Paul Rabinow. En: Rabinow P, Dreyfus H (Orgs.). Michel Foucault: uma trajetória filosófica. Rio de Janeiro: Forense Universitária; 1995. p.253-278.

8. Foucault M. Nietsche, a genealogia, a história. En: Foucault M. Arqueologia das ciências e história dos sistemas de pensamento. Rio de Janeiro: Forense Universitária; 2002. p. 260-281.
9. Foucault M. A Ordem do Discurso. $7^{\mathrm{a}}$ ed. São Paulo: Edições Loyola; 2001.

10. Dispõe sobre a participação da comunidade na gestão do Sistema Único de Saúde. Lei n ${ }^{\circ} .142$, de 28 de dez., 1990 [en línea]. [Consultado el 2 de febrero de 2009]. Disponible en: http://portal.saude.gov.br/ portal/arquivos/pdf/Lei8142.pdf.

11. Lima TCS, Mioto RCT. Procedimentos metodológicos na construção do conhecimento científico: a pesquisa bibliográfica. Rev Katál Florianópolis. 2007; 10(Supp.):37-45.

12. Stralen CJV. Notas a respeito de participação comunitária em programa de saúde [manuscrito]; 1974.

13. Stralen CJV, Sousa TB, Vieira LMF. A participação comunitária em programas de extensão da cobertura de serviços de saúde. XIV Congresso Brasileiro de Higiene e $1^{\circ}$ Congresso Paulista de Saúde Pública; 1977 out. 10-14; São Paulo, Brasil.

14. Stralen CJV. Movimentos sociais urbanos e a democratização dos serviços de saúde. Rev Adm Pública. 1983;17(3):38-45.

15. Anais da III Semana de Estudos Sobre Saúde Comunitária. Curitiba, 13 a 17 de abril; 1976.

16. Rabinow $P$, Dreyfus $H . A$ analítica interpretativa. En: Rabinow P, Dreyfus H (Orgs) Michel Foucault: uma trajetória filosófica. Rio de Janeiro: Forense Universitária; 1995. p.116-139.

17. Brasil. Ministério da Saúde. Anais da $7^{a}$ Conferência Nacional de Saúde. Brasília: Centro de Documentação do Ministério da Saúde; 1980.

18. Brasil. Ministério da Saúde. Secretaria de Políticas de Saúde. Projeto Promoção da Saúde: As Cartas de Promoção da Saúde. Brasilia: Ministério da Saúde; 2001.

19. Brasil. Ministério da Saúde. Anais da $8^{\text {a }}$ Conferência Nacional de Saúde. Brasília: Centro de Documentação do Ministério da Saúde; 1987.

20. OEA. Alianza para el Progresso. Documentos Oficiales de la OEA. Ser.H, XII, Rev.2. Washington DC: OEA; 1961.

21. OPAS. Reunión de Ministros de Salud - Grupo de Estudio - Informe final. Bol Oficina Sanit Panam. 1963;LV(1):1-49.

22. Donnângelo CF. Saúde e Sociedade. São Paulo: Livraria Duas Cidades; 1976.

23. Guevara CMS, et al. Participação Comunitária. Rev Adm Pública. 1983;17(3):87-99.

24. Quevedo E, Hernández M, Miranda N, Mariño C, Cardenas H, Wiesner C. La salud y el desarollo (19581974). Pap Pol abr. 1998;7:37-67.

25. Ferreira MAF. Entre a norma institucional e a ação coletiva: uma arqueologia da participação popular em saúde [Tesis]. Programa de Pós-Graduação em Saúde Coletiva da Faculdade de Ciências Médicas da UNICAMP. Campinas, SP: UNICAMP; 1992. 
26. Bógus CM. Participação popular em saúde: formação política e desenvolvimento. São Paulo: Annalube; FAPESP; 1999.

27. Fávero 0 . Uma pedagogia da participação popular: análise da prática educativa do MEB - Movimento de Educação de Base (1961/1966). Campinas, SP: Autores Associados; 2006.

28. Freire P. Educação como prática para a liberdade. $32^{\mathrm{a}}$ reimp. Rio de Janeiro: Paz e Terra; 2009.

29. Freire P. Pedagogia do oprimido. $48^{\mathrm{a}}$ ed. Rio de Janeiro: Paz e Terra; 2005.

30. OPAS. Pan Decenal para las Américas: Informe final de la III Reunión Especial de Ministros de Salud de las Americas; 1973.

31. OPAS. Resolución XXII sobre las Discusiones Técnicas Adoptada por la XXII Reunión del Consejo Directivo de la OPS. Bol Oficina Sanit Panam. 1974: 32-33.

32. Herrera JC. A planificação participante no desenvolvimento. Anais da III semana de estudos sobre saúde comunitária. Curitiba; 1976 abr. 13-17.

33. Dispõe sobre as condições para a promoção, proteção e recuperação da saúde, a organização e 0 funcionamento dos serviços correspondentes e dá outras providências Brasil. Lei $n^{\circ} 8.080$, de 19 de set., 1990 [en línea] [Consultado el 2 de febrero de 2009]. Disponible en: http://portal.saude.gov.br/portal/arquivos/pdf/LEl8080.pdf.

34. Somarriba MMG, Afonso MR. A relação estado-movimentos sociais urbanos: novas tendências; 1985.

35. Fleury S, organizador. Projeto Montes Claros: a utopia revisitada. Rio de Janeiro: ABRASCO; 1995.

36. Stralen CJV. The Struggle over a National Health Care System: the "movimento sanitário" and health policymaking in Brazil. Utrecht: FSW/RUU; 1996.

37. Escorel S, Moreira Mr. Participação social. En: Giovanella L, Escorel S, de Vasconcelos Costa Lobato L, de Carvalho Noronha J, de Carvalho Al, org. Políticas e sistema de saúde no Brasil. Rio de Janeiro: FIOCRUZ I CEBES; 2008. p. 979-1009.

38. Guizardi FL, Pinheiro R. Dilemas culturais, sociais e políticos da participação dos movimentos sociais nos Conselhos de Saúde. Ciênc Saúde Colet. 2005;11(3):797-805. 